\title{
Use of Spectral Analysis in the Detection of Frequency Differences in the Electrogastrograms of Normal and Diabetic Subjects
}

\author{
CATHERINE J. PFISTER, STUDENT MEMBER, IEEE, JOHN W. HAMILTON, NANCY NAGEL, \\ PAUL BASS, JOHN G. WEBSTER, FELLOW, IEEE, \\ AND WILLIS J. TOMPKINS, SENIOR MEMBER, IEEE
}

\begin{abstract}
Patients with long term insulin-dependent diabetes are frequently troubled by gastric complaints consisting of early satiety, bloating, nausea, and often episodic vomiting. We are interested in investigating the basal electrical rhythm (BER) of the stomach to determine if abnormalities of the BER occur in association with those gastric complaints.

We recorded the basal electrical signal of the stomach in nine patients with diabetic gastroparesis and in $\mathbf{1 1}$ normal volunteers. Since visual interpretation is difficult at times and somewhat subjective, we developed a microcomputer-based running spectral analysis technique (overlapping FFT's) to analyze the recordings. The interpretation of these data was aided by pseudo-three-dimensional and gray-scale graphics plots which we created on the microcomputer.

We found no significant differences between the two subject groups in the prefed state but found a significantly higher proportion of episodes of high frequency, or "tachygastria," in the diabetic group in the post fed state (15.4-6.2 percent). This difference was also reflected in the higher postfed mean "peak" frequency of the diabetics. Both diabetics and normals show an increase in the mean of the peak frequency from pre- to postfed states, but the normals do not show an increase in episodes of tachygastria.
\end{abstract}

\section{INTRODUCTION}

$\mathrm{T}$ HE stomach has an omnipresent electrical signal which signal paces the rhythm of gastric contractions when they occur [1]. This electrical signal is known by a variety of names, one of which is "basic electrical rhythm," or BER. The BER from the human stomach has been measured using a variety of electrode placement techniques, including sewing the electrodes directly onto the serosal surface of the stomach [2]-[12], passing the electrodes perorally into the stomach and either suctioning them to the mucosal lining [4], [7], [11]-[16] or af-

Manuscript received August 25, 1987; revised June 20, 1988. This work was supported in part by the University of Wisconsin's Medicine Research Fund, the Wisconsin Chapter of the American Diabetes Association, and a general research grant from the National Institutes of Health.

C. J. Pfister, J. G. Webster, and W. J. Tompkins are with the Department of Electrical and Computer Engineering, University of Wisconsin, Madison, WI 53706.

J. W. Hamilton and N. Nagel are with the Department of Medicine, University of Wisconsin, Madison, WI 53706.

P. Bass is with the School of Pharmacy, University of Wisconsin, Madison, WI 53706.

IEEE Log Number 8823289 fixing them by use of an external magnet [17], or placing them cutaneously on the abdominal surface [2], [12], [16]-[26]. All of these methods have revealed a human gastric electrical signal of approximately three cycles/ minute (cpm). The recordings are commonly termed "electrogastrograms,", or EGG's.

There have been reports in the literature of an abnormal BER in patients with chronic nausea and vomiting [9], [15], [28], in persons with brief episodes of nausea induced by motion [29], in patients with anorexia nervosa [30], and in diabetics with a syndrome known as diabetic gastroparesis [31]. The abnormalities of the BER reported in these investigations include tachygastria (high-frequency BER), tachyarrhythmia (unstable BER), bradygastria (low-frequency BER), and postprandial (postfed) power reduction of the BER. Diabetics who suffer from the syndrome of gastroparesis demonstrate markedly prolonged gastric emptying and repetitive vomiting. Our goal was to investigate long term diabetics with a history of such gastric complaints in an effort to further characterize the presence and frequency of abnormalities of the BER in these patients. However, routine recording of the BER is difficult because of the relatively small amplitude of the signal in comparison with other physiological signals (e.g., cardiac) as well as artifact from respiration and movement. This makes visual interpretation of the signal frequency in time domain records difficult.

We felt that the investigation of a possibly pathologic BER would be facilitated by a method that would allow measurement of the frequency of the signal over long periods of time. To accomplish this we developed a microcomputer-based version of a minicomputer-based technique previously applied to elastrogastrography called running spectral analysis [29], [37] to compute and display overlapping fast Fourier transformations (FFT's). This technique allows us to evaluate long recordings in the frequency domain, and was invaluable in the comparison of the electrogastrogram in nine patients with diabetic gastroparesis and a group of 11 normal volunteers of similar age without gastrointestinal symptoms. 


\section{Materials and Methods}

\section{A. Subjects}

This investigation was approved by the human subjects committee of the University of Wisconsin on November $20,1986$.

We recruited nine patients with a history of chronic insulin-dependent diabetes mellitus. Each of the subjects had a chronic history of early satiety, nausea, and intermittent vomiting, and all had one or more symptoms of end organ damage (five with peripheral neuropathy, three with renal failure status posttransplantation, and five with retinopathy). We also recruited 11 subjects of similar age without gastrointestinal symptoms or any history of gastric complaints (mean age for the diabetics was $44 \pm 12$ versus $41 \pm 18$ for the normals).

In an effort to examine the gastric function of the subjects, we had each subject undergo a radionuclide gastric emptying study on a day separate from his/her electrogastrogram. This was done by having the patient ingest two scrambled eggs labeled with $1 \mathrm{mCi}$ of technetium with one slice of toast and $8 \mathrm{oz}$ of orange juice. The subjects were positioned under a gamma camera and scanned for 120 min or until one-half emptying occurred. The diabetic subjects' mean one-half gastric emptying time was $146 \pm$ 29 (SEM) $\mathrm{min}$ as compared to $88 \pm 5 \mathrm{~min}$ for the normals.

\section{B. Recordings of the Electrogastrogram}

We have previously discussed extensively our method of recording of the electrogastrogram [27]. We asked the subjects to fast from midnight the night before the recording was to take place. We used both mucosal suction electrodes and cutaneous electrodes for the recording of the BER. We placed five electrodes over the upper abdomen: a central electrode in the midline, one-half the distance of the xiphoid to the umbilicus, four electrodes around the central electrode at the distance of two centimeters apart, and a reference electrode $5 \mathrm{~cm}$ above the right ankle. Each electode site was lightly abraded prior to electrode placement. We used pairs of these abdominal electrodes to provide a differential signal for the recording.

We then placed the suction electrode device perorally into the stomach and directed it fluoroscopically to the prepyloric-gastric antrum. This electrode consists of a 1 $\mathrm{cm}$ silicone rubber cup case with three $6 \mathrm{~mm}$ long electrodes spaced $120^{\circ}$ apart (Model E214, In Vivo Metric Systems, Healdsburg, CA). The tip of each electrode has a small $\mathrm{Ag} / \mathrm{AgCl}$ pellet. An opening in the cup leads to a silicone rubber tube which was used for suctioning the electrodes against the gastric mucosa. We then used pairs of the electrodes within the suction cup for recording a differential signal.

A catheter containing miniaturized strain gauge pressure transducers (Millar Institute, Houston, TX) was attached to the suction device to measure intragastric pressure.

In order to obtain an analog record of the electrogastro- gram, we used a six-channel Sensormedics R611 chart recorder (SensorMedics Corporation, Anaheim, CA). We created a bandpass filter to decrease the interference from cardiac electrical activity and baseline drift. This was done by using the adjustable internal low-pass filter of the chart recorder at a cutoff of $0.12 \mathrm{~Hz}$, or $7.2 \mathrm{cpm}$, and by creating a high-pass filter by placing capacitors in series with the input leads which, together with the input impedance of the recorder, resulted in a low-frequency cutoff of 0.024 $\mathrm{Hz}$, or $1.44 \mathrm{cpm}$. In addition to the chart recording, we recorded the analog signal on an FM tape recorder at a tape speed of $15 / 16 \mathrm{in} / \mathrm{s}$ for purposes of digitization at a later time.

Partway through the recording period, we fed the subjects a standard meal of $148 \mathrm{ml}$ (173 calories) of pudding and milk at room temperature. Recording took place for $78.8 \pm 3.8 \mathrm{~min}$.

\section{Analysis}

We individually scored the chart recordings for the presence of $3 \mathrm{cpm}$ signal and evidence of any abnormalities such as patterns of high frequency (greater than 3.5 $\mathrm{cpm}$ ), low frequency (less than $2.5 \mathrm{cpm}$ ), or irregular rhythms which were present in both the mucosal and cutaneous recordings.

We digitized the data from the FM tapes using an IBMPC AT microcomputer with a LabMaster 16 channel, 12 bit analog-to-digital converter (Scientific Solutions, Solon, $\mathrm{OH}$ ). The tapes ran at 16 times real time and sampling took place at 16 samples/s (sps) which corresponds to real-time sampling of 1 sps. We used a program based on the Cooley-Tukey algorithm [32] to compute 256 point FFT's for the running spectral analysis, with the data first undergoing modification by application of a Hamming window to reduce leakage. Each FFT represents approximately $4 \mathrm{~min}$ of data and was recomputed every 60 data points for an overlap of $1 \mathrm{~min}$, or 77 percent. Power spectra were obtained by squaring the magnitude of the FFT's and the series of spectra was then stored in a data file on the hard disk of the AT. We also wrote graphics programs for a pseudo-3-D plot and a gray-scale plot to display the running spectral analysis.

We also performed statistical analysis of the data involving calculation of mean frequency and average " peak frequency" along with their variances for each subject. We define "peak frequency" to be the frequency at which the highest power in an individual spectrum occurred (Fig. 1). Postprandial-to-fasting power ratios were also computed. Significance of differences between the normal and diabetic groups was obtained using the unpaired $t$ test. We wrote all of the above-mentioned computer programs in the $C$ language.

\section{Graphics Algorithms}

1) Pseudo-3-D Representation: In order to present time, frequency, and power information to the viewer, we wrote a program to display the FFT's in pseudo-3-D form which gives the illusion that the display has a three-di- 


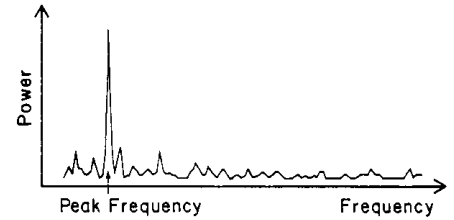

Fig. 1. The arrow points to the "peak" frequency in this particular power spectrum.

mensional coordinate system, with time along the $x$ axis, frequency along the $y$ axis, and power along the $z$ axis. To show this on a two-dimensional graphics printout, each subsequent power spectrum, representing later and later time periods, has its orgin shifted in both the $x$ and $y$ directions. The more the origins are shifted in the $y$ direction with respect to the $x$ direction, the sharper the viewing angle, which allows for better separation of the individual spectra but makes for greater difficulty in following a frequency component through several time periods.

2) Gray-Scale Representation: In the gray-scale plots, a two-dimensional coordinate system is used with the $x$ axis representing frequency, the $y$ axis representing time, and the intensity of the points representing spectral power. Therefore, the darker the point, the greater the power of the spectrum at that point. This representation has both advantages and disadvantages compared to the pseudo3 -D representation. The gray-scale does not provide as great a degree of resolution of amplitude as does the pseudo3-D representation but it does facilitate observation of frequency shifts.

In our "pseudo" gray-scale representations of power spectra, each data point is represented by a $5 \times 5$ matrix of pixels. Thus, there can be 26 levels of intensity-from all pixels off to all pixels on. The maximum of all the data values in the spectra to be plotted is first obtained, and this value is given an intensity level of 25 , which means 25 pixels in the matrix will be turned on. All other values are scaled proportionally to this maximum and rounded to an integer value which represents an intensity level.

\section{Results}

We found that the statistics of the internal and external data matched well for the normal subjects; however, we had trouble obtaining consistent recordings from the internal electrodes of the diabetics. These patients were often nauseated and retching, or had retained gastric contents. This resulted in the frequent loss of suction in the internal electrode device with accompanying loss of contact between the electrodes and the mucosa. Because of this, we will report only data from external electrodes in our comparison of the results from the two groups.

Manually scoring the data in the time domain is cumbersome. We found only one clear episode of tachygastria where a clear repetitive segment of a rate faster then 3.5 was demonstrated in both the suction and cutaneous electrodes (Fig. 2). Fig. 3 shows the pseudo-3-D and grayscale plots for the patients whose time-domain record is

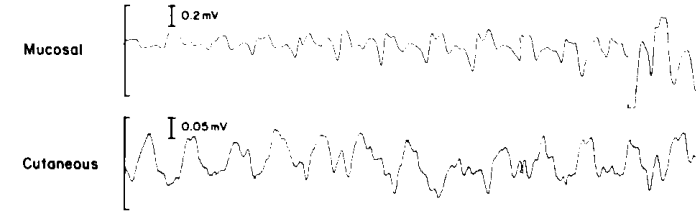

(a)
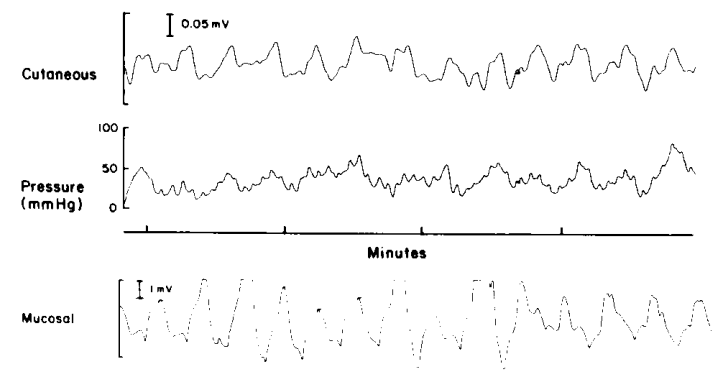

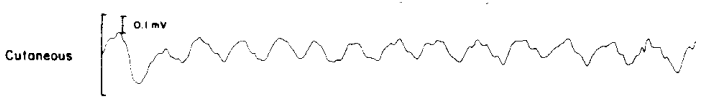

(b)
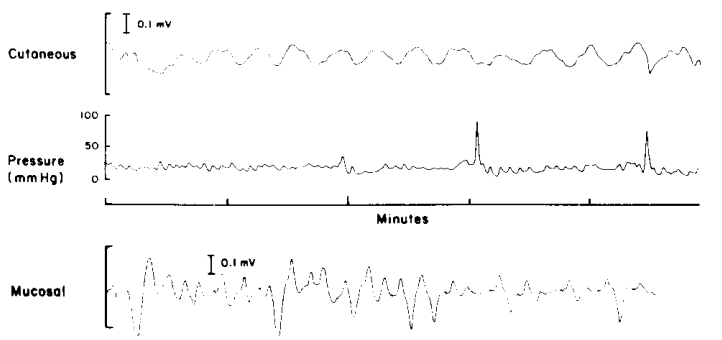

Cutaneous $\left[\begin{array}{cc} & I^{0.05 \mathrm{mv}} \\ \therefore & \cdots\end{array}\right.$

(c)

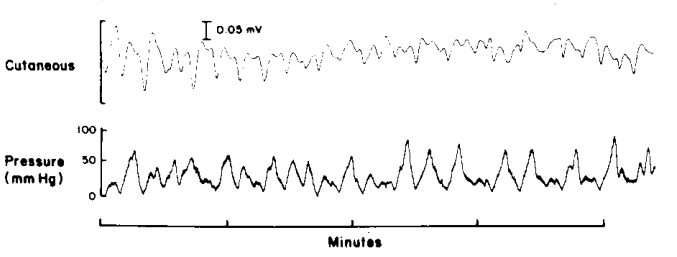

Fig. 2. The normal state and tachyarrhythmia in the time domain. (a) A normal volunteer demonstrating a $3 \mathrm{cpm}$ BER in both the mucosal and the cutaneous recordings from two different electrode pairs. (b) Demonstration of a normal BER in a diabetic patient. (c) Demonstration of a tachyarrhythmia manifested not only in the mucosal and cutaneous recordings of the BER but also in the intragastric pressure recording.

shown in Fig. 2(c). In the other patients, we were unable to identify instances where a regular signal of abnormal frequency replaced the usual $3 \mathrm{cpm}$ signal for any significant stretch of time. Often the $3 \mathrm{cpm}$ would be replaced by periods of irregular rhythms. While it is possible these episodes could be an arrhythmia it is difficult to say that it is not artifact. We did observe instances where the 3 cpm signal was replaced by a clearly higher frequency (Fig. 4), but the condition usually did not last long enough to be seen in more than 3-4 consecutive spectra, and could be identified in both diabetics and normals.

When we compared the statistical results from the two groups, we did observe a slightly higher mean frequency 


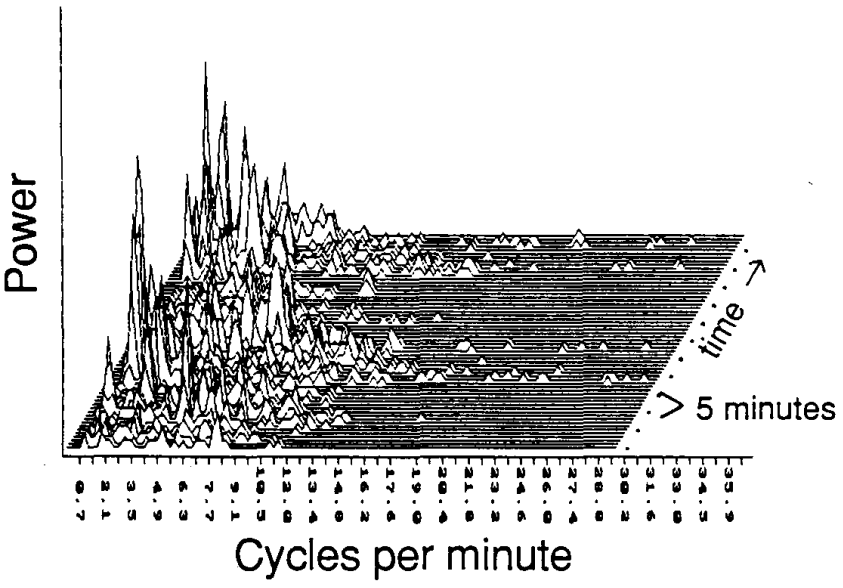

(a)

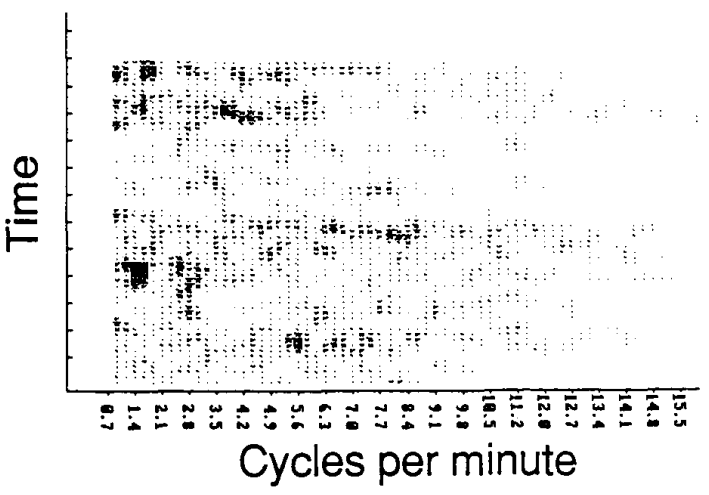

(b)

Fig. 3. Running spectral analysis of the EGG of the same diabetic patient whose time-domain record exhibiting tachyarrhythmia is shown in Fig. 4(c). (a) The pseudo-3-D plot. (b) The gray-scale plot.

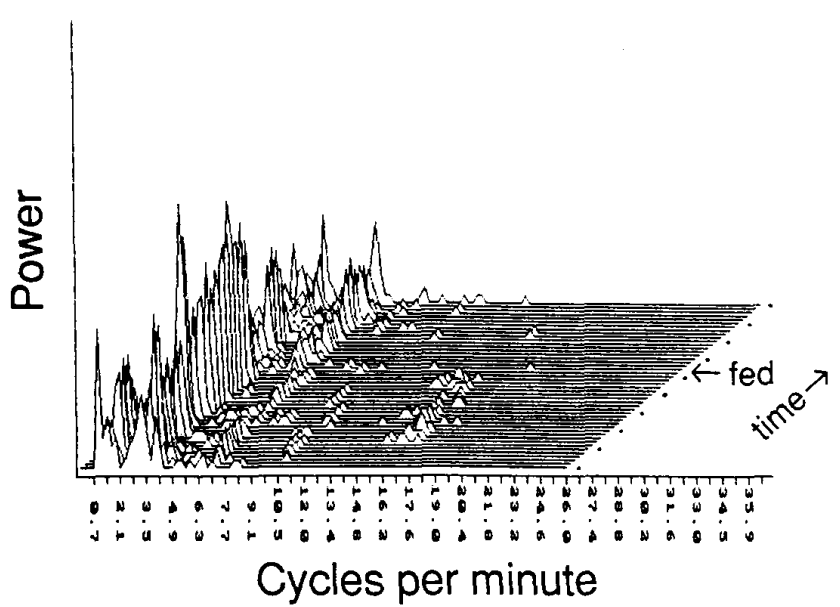

(a)

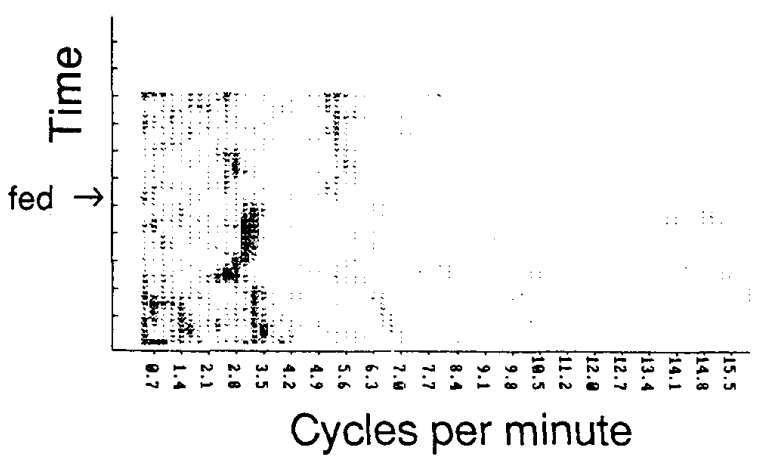

(b)

Fig. 4. (a) Pseudo-3-D and (b) gray-scale plots from a diabetic subject exhibiting an increase in episodes of tachygastria in the postfed state.

in the diabetics than in the normals in both the prefed and postfed states but the difference was not shown to be statistically significant $(2.9-2.85 \mathrm{cpm}$ prefed and 3.05-2.95 cpm postfed). However, as seen in Table I, there was a statistically significant difference in the postfed peak frequencies with the diabetics showing a mean peak value of $2.91 \mathrm{cpm}$ compared to $2.60 \mathrm{cpm}$ for normals. There was no such differences in prefed peak frequency $(2.595 \mathrm{cpm}$ for diabetics and $2.495 \mathrm{cpm}$ for normals).

Upon closer examination, we found that this averaged postfed peak frequency difference did not represent a slight change in the frequency BER in the diabetics, but rather a shift of the peak frequency for several periods into a higher frequency range. We defined the low range to be $1.0-2.5 \mathrm{cpm}$, the midrange (or normal range) of $2.5-3.5$, and the high range $3.5-7.0 \mathrm{cpm}$. Table II shows that diabetics had a significantly higher percentage of peak frequencies in the high range in the postfed state as com- pared to normals, 15.4-6.2 percent, while there was little difference in the 2.5-3.5 cpm, or normal, range (56.559.2 percent). The occurrence of the peak frequency in the high range could be termed "tachygastria" and that in the low, "brandygastria.'

Using the paired $t$ test, we found that the peak frequencies increase significantly from the pre- to postfed states in both the diabetic and normal groups. Again, upon closer examination of the data, the change in peak frequency proved to be the result not of a small shift in the BER, but of the presence of additional peaks in the lower and higher ranges. In normals, the incidence of the peak frequencies in the nigh range drops slightly (although not significantly) from the pre- to postfed state, 7.3 to 6.2 percent, while the low-range occurrences decrease from 43.4 to 34.6 percent. Conversely, in diabetics the percentage of peak frequencies in the high range increases significantly from the prefed to postfed state, 5.3 to 15.4 
TABLE I

Mean Peak Frequencies in Normals and Diabetics in Prefed and POSTFED STATES.

\begin{tabular}{|c|c|c|c|}
\hline & Norma1s & Diabetics & $\begin{array}{l}\text { Significance of } \\
\text { unpaired t-test }\end{array}$ \\
\hline \multicolumn{4}{|l|}{ Prefed mean } \\
\hline peak frequency & 2.495 & 2.595 & $p>0.05$ \\
\hline \multicolumn{4}{|l|}{ Postfed mean } \\
\hline peak frequency & 2.601 & 2.906 & $p<0.05$ \\
\hline
\end{tabular}

TABLE II

Occurrence of Tachygastria in Normals and Diabetics in the Prefed AND Postfed STATES.

\begin{tabular}{lccc}
\hline \hline & & & Significance of \\
Normals & Diabetics & $p>0.05$ \\
Percentage & & & \\
prefed tachygastria & 7.38 & 5.38 & \\
Percentage postfed & & & $\mathrm{p}<0.05$ \\
tachygastria & 6.28 & 15.48 &
\end{tabular}

percent, while that of the low range decreases from 34.0 to 28.1 percent.

Thus, while both normals and diabetics exhibit a prefedto-postfed increase in peak frequency, the underlying reasons for the change are quite different in the two cases. In the diabetics, the shift of the mean peak frequency is due to a sharp increase in high-range peaks along with a slight decrease in low- and midrange peaks. In normals the shift is due almost exclusively to a change of peaks from the low to midrange with the incidence of high-range peaks changing very little.

With regard to postfed changes in power, we found a slightly higher postfed-to-prefed power in normals than in diabetics but the difference was not significant (1.1560.929 ). Fig. 5(a) shows that the pseudo-three-dimensional plot from a subject exhibiting distinct postprandial power increase while Fig. 5(b) shows a more representative subject with a slight, or unremarkable power increase.

We also found no differences in the variances of the mean and peak frequencies between the two groups. A difference in variance might have indicated an instability of the BER.

\section{Discussion}

The goal of this study was to apply the running spectral analysis technique to long recordings of the EGG from normals and diabetic subjects in an attempt to bring to light frequency differences that have been indicated from a previous report [31]. These differences are often not readily apparent from time domain observations. Work in the time domain has been impeded by the low signal amplitude of the EGG and contamination by various noise sources including the EGG, which is approximately ten

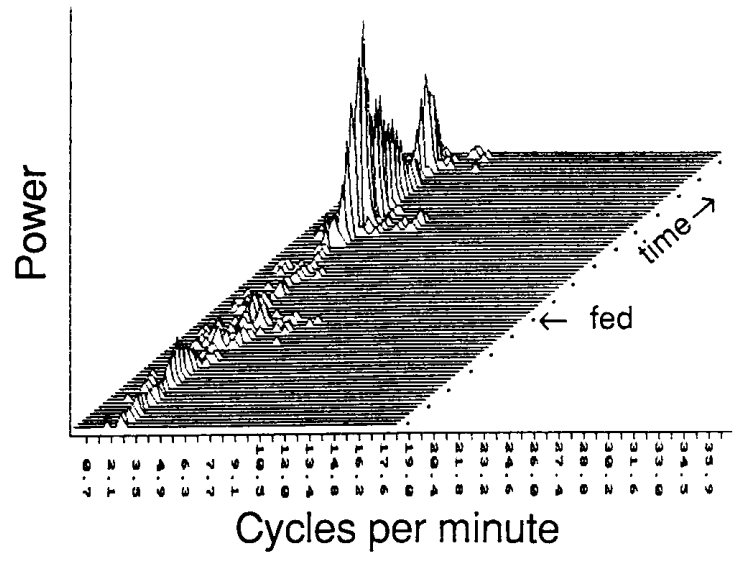

(a)

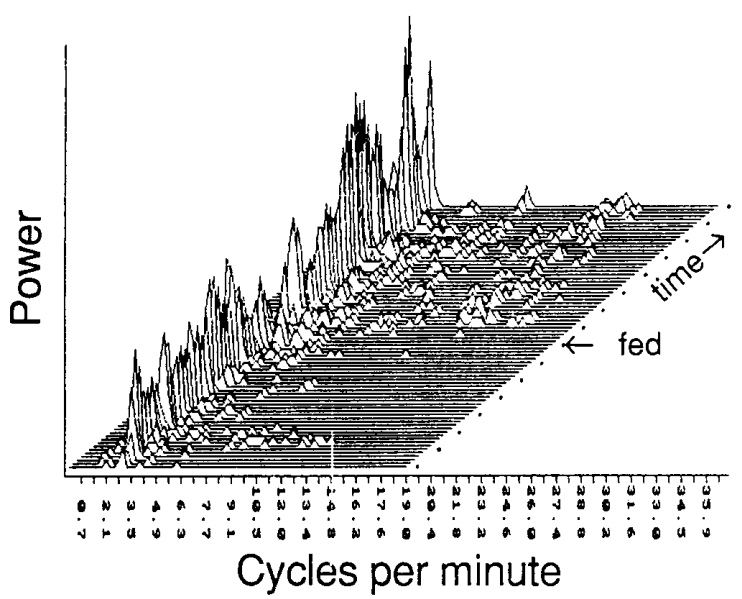

(b)

Fig. 5. Subjects showing (a) a large postfed power increase and (b) a smaller but more representative increase.

times stronger than the EGG, the EMG, respiration, other motion artifacts, and other slowly varying potentials originating from elsewhere in the GI tract. Noise tends to vary inversely with frequency, and the low $(0.5 \mathrm{~Hz})$ frequency of the EGG make noise contamination a particular problem.

Several methods have been used to minimize the noise interference with varying degrees of success, including adaptive filters [33], [34], phase-locked loops [35], autoregressive modeling [14], and signal averaging [36]. Some of the interference occurs at frequencies much higher than those in the EGG, which is the case with much of the ECG, EMG, and to some extent, respiration. Analysis is thus facilitated in the frequency domain where the signals of different frequency are separated, and many investigators use the fast Fourier transform (FFT) to obtain the frequency information [16], [29], [37], [38].

One of the problems with using the FFT is that there is a loss of time information. Several minutes of data are needed to compute the transform, which then gives the frequencies present in that time segment. However, there 


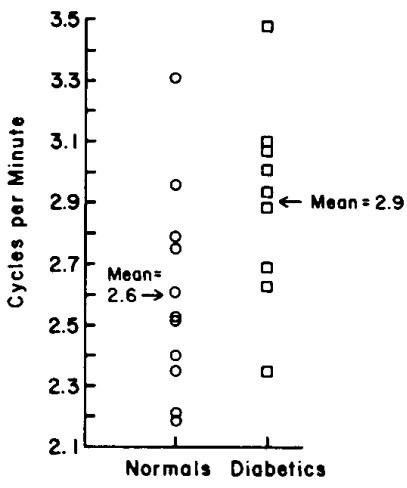

Fig. 6. The overlap of the postfed mean peak frequencies for the nine diabetic and 11 normal subjects.

is no indication of when in those several minutes the different frequencies occurred. This problem has been partially overcome by using overlapping FFT's in running spectral analysis technique, which allows frequency domain analysis of long stretches of the data without the total loss of time information [29], [37], [38]. The graphics for this type of analysis has in the past been performed mainly on mini- or main-frame computers, thereby limiting the access to this technique by many investigators. We were successful in achieving the same analysis on a microcomputer, writing relatively simple graphics programs for pseudo-3-D gray-scale plots. This method allows for the comparison of the normal and diabetic groups in a way that was not possible from visual interpretation of the time-domain records. While the spectral analysis reveals a significant difference in postfed-mean-peak frequencies in the two groups, there is considerable overlap of the individual subjects (Fig. 6).

Our hypothesis that there would be an increase in the number of episodes of tachygastria in diabetics over normals has thus been supported, albeit the appearance of the tachygastria was different than expected. Instead of sustained periods of high frequency, the phenomenon apparently manifests itself as irregular bursts of high frequencies interpersed with the stable $3 \mathrm{cpm}$ signal in the postfed state (Fig. 6). This abnormality of the controlling electrical signal of the antral muscle of the stomach may be the result of underlying neuropathy and may serve to set up abnormal contraction patterns that could relate to nausea or vomiting episodes, especially in the time-span shortly after feeding.

\section{Conclusions}

We conclude that there are significant differences between the EGG's of diabetic gastroparetic and normal subjects. These differences are reflected in the higher mean peak frequency of the diabetics over normals in the postfed state and in the increase of occurrence of highrange peak frequencies (tachygastria) from pre- to postfed states in diabetics. These differences are not readily observable from manual scoring of the data, but become apparent after application of the running FFT technqiue discussed above.

\section{REFERENCES}

[1] J. H. Meyer, "Motility of the stomach and gastroduodenal junction," in Physiology of the Gastrointestinal Tract, 2nd ed., L. R. Johnson, Ed. New York: Raven, 1987

[2] T. S. Nelsen and S.Kohatsu, "Clinical electrogastrography and its relationship to gastric surgery," Amer. J. Surg., vol. 116, pp. 215$222,1968$.

[3] J. A. McIntyre, M. Deitel, M. Baids, and S. Jalil, "The human electrogastrogram at operation: A preliminary report," Can. J. Surg., vol. 12 , pp. 275-284, 1969.

[4] N. K. Kwong, B. H. Brown, G. E. Whittaker, and H. L. Duthie "Electrical activity of the gastric antrum in man,"' Brit. J. Surg., vol. 57, pp. 913-916, 1970.

[5] J. Dauchel, J. C. Schang, J. Kachelhoffer, R. Elroy, and J. F. Grenier, "Gastrointestinal myoelectrical activity during the postoperative period in man," Digest., vol. 14, pp. 293-303, 1976.

[6] H. L. Duthie, N. K. Kwong, B. H. Brown, and G. E. Whittaker, "Pacesetter potential of the human gastroduodenal junction," Gut vol. 12 , pp. 250-256, 1971

[7] D. Couturier, C. Roze, J. Paolaggi, and C. Debray, "Electrical activity of the normal human stomach: A comparative study of recording obtained from the serosal and mucosal sides," Amer. J. Dig. Dis., vol. 17, pp. 969-976, 1972.

[8] R. A. Hinder and K. A. Kelly, "Human gastric pacesetter potential: Site of origin, spread and response to gastric transection and proximal gastric vagotomy,"'Amer. J. Surg., vol. 133, pp. 29-33, 1977.

[9] R. L. Telander, K. G. Morgan, D. L. Kreulen, P. F. Schmalz, K. A Kelly, and J. H. Szurszewski, "Human gastric atony with tachygastria and gastric retention," Gastroenterol., vol. 75, pp. 497-501, 1978 .

[10] K. Sanders, R. Menguy, W. Chey, C. You, K. Lee, K. Morgan, D. Kreulen, P. Schmalz, T. Muir, and J. Szurszewski, "One explanation for human antral tachygastria,"' Gastroenterol., vol. 76, p. 1234, 1979

[11] C. J. Stoddard, R. H. Smallwood, and H. L. Duthie, "Electrical arrhythmias in the human stomach," Gut, vol. 22, pp. 705-712, 1981.

[12] B. H. Brown, R. H. Smallwood, H. L. Duthie, and C. J. Stoddard, "Intestinal smooth muscle electrical potentials recorded from surface electrodes," Med. Biol. Eng., vol. 13, pp. 97-102, 1975.

[13] H. Monges and J. Salducci, "A method of recording the gastric electrical activity in man," Amer. J. Dig. Dis., vol. 15, pp. 271-276, 1970.

[14] D. A. Linkens and S. P. Datardina, "Estimation of frequencies of gastrointestinal electrical rhythms using autoregressive modeling," Med. Biol. Eng. Comput., vol. 16, pp. 262-268, 1978.

[15] C. H. You, W. Y. Chey, and R. Menguy, "Electrogastrographic study of patients with unexplained nausea, bloating, and vomiting," Gastroenterol., vol. 79, pp. 311-314, 1980.

[16] B. E. Bellahsene, J. W. Hamilton, J. G. Webster, P. Bass, and M. Reichelderfer, "An improved method for recording and analyzing the electrical activity of the human stomach," IEEE Trans. Biomed. Eng. vol. BME-32, pp. 911-915, Nov. 1985

[17] T. L. Abell and J.-R. Malagelada, "Glucagon-evoked gastric dysrhythmias in humans shown by an improved electrogastrographic technique," Gastroenterol., vol. 88, pp. 1982-1940, 1985.

[18] I. S. Rabin, J. J. Kneisel, R. Taylor, H. M. Leinon, E. M. Thompson, and R. H. Smithwick, "Measurement of the electropotentials of the stomach," Surg. Forum A. Coll. Surg., vol. 1, pp. 69-73, 1950.

[19] E. N. Goodman, I. A. Ginsberg, and M. A. Robinson, "An improved apparatus for measuring the electrogastrogram," Science, vol. 113 , pp. $682-683,1951$.

[20] H. S. Morton, "The potentialities of the electrogastrograph," (Hunterian Lecture), Ann. R. Coll. Surg. Eng., vol. 15, pp. 351-373, 1954.

[21] E. N. Goodman, H. Colcher, G. M. Katz, and C. L. Dangler, "The clinical significance of the electrogastrogram," Gastroenterol., vol. 29 , pp. 598-607, 1955.

[22] M. A. Sobakin, I. P. Smirnov, and L. N. Mishin, "Electrogastrog raphy," IRE Trans. Bio-Med. Electron., vol, 9, 129, 1962.

[23] Y. Tanaka and M. Yaniyasawa, "The electrogastrography for the stomach and its clinical application," Japan. J. Electron. Biol. Eng. vol. 1, p. $309,1963$.

[24] A. Martin, J. Moline, and J. Murat, “Apport de L'Ectrosplanchnographie (E.S.G.) Au diagnostic preoperatoire d'une ulceration gastrique," Press Med., vol. 79, pp. 1277-1278, 1971.

[25] V. F. Tiemann and P. Reichertz, "Uber das intestinal Elektrogramm (E.I.G.) und seine Bedeutung fur die Klinik,"’ Med. Klin., vol. 14, pp. 654-667, 1959.

[26] T. J. Myers, P. Bass, J. G. Webster, A. B. Fontaine, and A. Miyau- 
chi, "Human surface electrogastrograms: AC and DC measurements," Ann. Biomed. Eng., vol. 12, pp. 319-333, 1984.

[27] J. W. Hamilton, B. E. Bellahsene, M. Reichelderfer, J. G. Webster, and P. Bass, "Human electrogastrograms: Comparison of surface and mucosal recordings," Dig. Dis. Sci., vol. 31, pp. 33-39, 1986.

[28] C. H. You, W. Y. Chey, K. Y. Lee, R. Menguy, and A. Bortaff, "Gastric and small intestinal myoelectric dysrhythmia associated with chronic intractable nausea and vomiting," Ann. Intern. Med., vol. $95, \mathrm{pp}, 449-451,1981$

[29] R. M. Stern, K. L. Koch, W. R. Stewart, and I. M. Lindblad, "Spectral analsysis of tachygastria recorded during motion sickness," Gastroenterol., vol. 92, pp. 92-97, 1987

[30] T. L. Abell, A. R. Lucas, M. L. Brown, and J.-R. Malagelada, "Gastric electrical dysrhythmias in anorexia nervosa (AN)," Gastroenterol., vol. 88, p. $1300,1985$.

[31] T. L. Abell, M. Camilleri, and J.-R. Malagelada, "High prevalance of gastric electrical dysrhythmias in diabetic gastroparesis," Gas troenterol., vol. 88, p. 1299, 1985

[32] J. W. Cooley and J. W. Tukey, "An algorithm for the machine calculation of complex Fourier series,"'Math. Computat, vol. 19, pp. 297-301, 1964.

[33] M. A. Kentie, E. J. van der Schee, J. L. Grashuis, and A. J. P. M Smout, "Adaptive filtering of canine electrogastrographic signals, Part 1: System design,' Med. Biol. Eng. Comput., vol. 19, pp. 759-764, 1981.

[34] J. B. Levy and D. A. Linkens, "Spectral analysis of short-time biomedical data using adaptive filters," Proc. IEE, vol. 131, pp. 164169,1984

[35] R. H. Smallwood, “Analysis of gastric electrical signals from surface electrodes using phaselock techniques: Part 1: System design,"' Med. Biol. Eng. Comput., vol. 16, pp. 507-512, 1978

[36] A. C. Volkers, E. J. van der Shee, and J. L. Grashuis, “Electrogastrography in the dog: Waveform analysis by a coherent averaging technique," Med. Biol. Eng. Comput., vol. 21, pp. 56-64, 1983.

[37] E. J. van der Schee, A. J. P. M. Smout, and J. L. Grashuis, "Application of running spectrum analysis to electrogastrographic signals recorded from dog and man," in Motility of the Digestive Tract, $\mathrm{M}$ Wienbeck, Ed. New York: Raven, 1982

[38] E. J. van der Schee and J. L. Grashuis, "Running spectrum analysis as an aid in the representation and interpretation of electrogastrographic signals," Med. Biol. Eng. Comput., vol. 25, pp. 57-62, 1987.

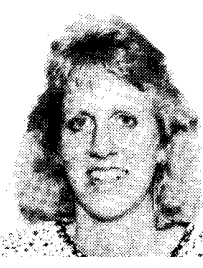

Collins, CO
Catherine J. Pfister (S'86) received the B.S. degree in biological sciences from Indiana Univer sity, Bloomington, in 1981 . She received the M.S degrees in biomedical engineering and electrical engineering from the University of Wisconsin, Madison, in 1987 and 1988, respectively.

From 1981 to 1984 she worked in the recombinant DNA research lab at Abbott Laboratories, North Chicago, IL. Currently, she is employed as an R\&D engineer in the Graphics Technology Division of the Hewlett-Packard Corporation, Fort

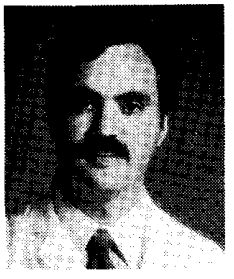

John W. Hamilton received the Bachelor's degree in biology in 1974 and the M.D. degree in 1978 , both from the University of Illinois, Chicago.

He did his residency in internal medicine from 1978 to 1981 and was a Chief Medical Resident in 1981 at the University of Connecticut, Farmington. He was a Gastroenterology Fellow at the University of Wisconsin, Madison, from 1981 to 1983. He is presently an Assistant Professor of Medicine in the section of Gastroenterology at the University of Wisconsin, Madison. His current interests lie in the field of gastric motitity esophageal motility. He has previously done work in gastrointestinal absorption and in endoscopy.

Nancy Nagel, photograph and biography not available at the time of publication.
Paul Bass was born in Canada. He received the B.S.P. degree in pharmacy M.A. degree in pharmacology from the University of British Columbia, Vancouver, B.C., Canada, and the Ph.D. degree from McGill University, Montreal, P.Q., Canada, in 1957

He was a postdoctoral student for 12 months in the Department of Physiology and Biochemistry, McGill University, and Fellow for 18 months in the gastrointestinal section of the Department of Physiology, Mayo Foundation. In 1960 he joined Parke, Davis, and Company, Research Laboratories, Ann Arbor, MI, where he assumed the position of Director of the Gastrointestinal Pharmacology Section. During this period, he was also affiliated with the Department of Pharmacology, School of Medicine, University of Michigan, Ann Arbor. He is currently a Professor with the School of Pharmacy and the Department of Pharmacology, School of Medicine, University of Wisconsin, Madison. His research interests include the area of gastrointestinal motility, secretion, and absorption, as well as the autonomic nervous system and smooth muscle pharmacology.

Dr. Bass is a member of the American Society for Pharmacology and Experimental Therapeutics, the American Gastroneterology Association, and several other societies.

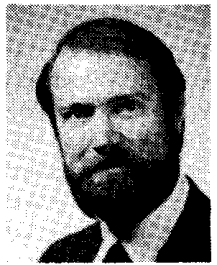

John G. Webster (M'59-SM'69-F'86) received the B.E degree from Comell University, Ithaca, NY, in 1953, and the M.S.E.E. and Ph.D. degrees from the University of Rochester, Rochester, NY, in 1965 and 1967, respectively.

$\mathrm{He}$ is a Professor of Electrical and Computer Engineering at the University of Wisconsin, Madison. In the field of medical instrumentation he teaches undergraduate, graduate, and shor courses, and does research on electrodes, biopotential amplifiers, impedance measurements, and tactile sensors for medicine and robotics. He is coauthor, with B. Jacobson, of Medicine and Clinical Engineering (Englewood Cliffs, NJ: PrenticeHall, 1977). He is Editor of Medical Instrumentation: Application and Design (Boston, MA: Houghton Mifflin, 1978). He is coeditor, with A.M. Cook, of Clinical Engineering: Principles and Practices (Englewood Cliffs, NJ: Prentice-Hall, 1979), with W. J. Tompkins, of Design of Microcomputer-Based Medical Instrumentation (Englwood Cliffs, NJ: Prentice-Hall 1981), with A.M. Cook, of Therapeutic Medical Devices: Application and Design (Englewood Cliffs, NJ: Prentice-Hall, 1982), with A. M. Cook, W. J. Tompkins, and G. C. Vanderheiden, of Electronic Devices for Rehabilitation (New York: Wiley, 1985), and with W. J. Tompkins of Interfacing Sensors with the IBM PC (Englewood Cliffs, NJ: Prentice-Hall, 1988). He is Editor of Encyclopedia of Medical Devices and Instrumentation (New York: Wiley, 1988), and Tactile Sensors for Robotics and Medicine (New York: Wiley, 1988).

Dr. Webster has been a member of the IEEE-EMBS Administrative Committee and Associate Editor, Medical Instrumentation, of the IEEE Transactions on Biomedical EngineERING. He is a member of the NIH Surgery and Bioengineering Study Section.

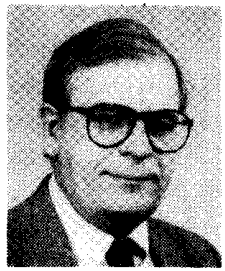

Willis J. Tompkins (S'61-M'66-SM'77) received the B.S. and M.S. degrees in electrical engineering from the University of Maine, Orono, in 1963 and 1965, respectively, and the Ph.D. degree in biomedical electronic engineering from the University of Pennsylvania, Philadelphia, in 1973.

From 1965 to 1968 , he was an Electrical Engineer at Sanders Associates, Inc., Nashua, NH, where he worked on research and development of data storage systems. He was employed from 1973 to 1974 at the Hospital of the University of Pennsylvania as a Biomedical Engineer. Since 1974, he has been on the Faculty of the University of Wisconsin, Madison. Currently, he is Associate Chairman for Undergraduate Activities and Professor of Electrical and Computer Engineering; he teaches undergraduate, graduate, and short courses on the topic of computers in medicine. His research interests include microcomputer-based medical instrumentation applications and on-line biomedical computing. He is coeditor, with J. G. Webster, of the textbooks, Design of Microcomputer-Based Medical Instrumentation, (Englewood Cliffs, NJ: Prentice-Hall, 1981) and Interfacing Sensors to the IBM PC, (Englewood Cliffs, NJ: Prentice-Hall, 1981). He is coeditor with J. G. Webster, A. M. Cook, and G. C. Vanderheiden of the textbook, Electronic Devices for Rehabilitation, (New York: Wiley, 1985).

Dr. Tompkins is currently the President of the IEEE Engineering in Medicine and Biology Society. He is also a member the IEEE Computer Society, the Association for the Advancement of Medical Instrumentation, the Biomedical Engineering Society, and the American Society for Engineering Education. He is a Registered Professional Engineer in Wisconsin. 